\title{
CASE OF INTEREST
}

\section{Delayed Bile Peritonitis Following Abdominal Stab Wounds}

\section{Introduction}

BILE peritonitis is a comparatively rare abdominal catastrophe which occasionally results from abdominal trauma.

The following case is of interest in that the onset of symptoms was delayed for six days after the infliction of penetrating stab wounds of the upper abdomen.

\section{Case history}

A professional footballer, J.H. aged 19 years, was involved in a Saturday evening brawl during which he received two stab wounds of the upper abdomen. He was subsequently taken to the Casualty Department of a nearby hospital and examination revealed two $1 \mathrm{~cm}$ wounds symmetrically situated below the costal margin in each hypochondrium. These were thought to be superficial, and after admission for overnight observation, he was allowed to return home.

He remained well, apart from some stiffness of the abdominal muscles, until the following Friday when he awoke in the early morning with abdominal pain. This was described as a cramp, situated mainly in the right lower quadrant, and was continuous but with intermittent severe exacerbation lasting for about 15 minutes during which the muscles of the right side of the abdomen became rigid. There was associated anorexia and nausea, but no vomiting. He was referred for admission some six hours after the onset of symptoms.

On examination, he was apyrexial, pulse 60 per minute, and blood pressure $150 / 80$ $\mathrm{mmHg}$. There was pronounced foetor oris and abdominal tenderness, principally in the right iliac fossa, with guarding and rebound tenderness. The bowel sounds were normal and rectal examination revealed an empty rectum with tenderness anteriorly and to the right. His white cell count was $10.600 \mathrm{~mm}^{3}$ and straight $\mathrm{X}$-rays of the abdomen revealed no abnormality.

The physical signs suggested acute appendicitis and the abdomen was opened through a grid-iron incision in the right iliac fossa. On incising the peritoneum, there was a gush of bile from the wound which was, therefore, closed and formal laparotomy carried out through a right paramedian incision. A $4 \mathrm{~mm}$ hole was found in the fundus of the gall bladder the adjacent wall being indurated and oedamatous. Inspection of the parietal peritoneum showed that both stab wounds had penetrated the peritoneal cavity, while that on the right side lay directly above the fundus of the gall bladder and was undoubtedly the cause of the perforation. Cholecystectomy was performed and the abdomen closed with drainage.

His subsequent progress was entirely uneventful and he was discharged home from hospital on the tenth postoperative day.

\section{Comment}

Pridgen et al (1967) analysed 465 cases of penetrating abdominal injury of which 70 per cent were stab wounds and found that the entry wound in 33 per cent was situated 
in the right upper quadrant. Despite this the gall bladder was injured in only 2.1 per cent of cases, a similar incidence to that found by Hall et al (1956) in 4,905 cases of abdominal trauma collected from the literature.

Gordon Taylor (1944) considering that the anatomical disposition of the gall bladder rendered it unlikely to be the sole viscus injured by any penetrating wound, and Hall et al (1956) reviewing 25 patients with traumatic rupture of the gall bladder admitted to a single hospital found that in only 5 patients ( 20 per cent) was the gall bladder alone injured.

In the case described above, the onset of symptoms was delayed until the sixth day following wounding. Although histological examination was somewhat unsatisfactory due to autolysis resulting from delayed fixation, the gall bladder wall in the region of the perforation was inflamed and infiltrated with plasma cells. It is suggested that laceration of the fundus was followed by local inflammation and subsequent necrosis with leakage of bile into the peritoneal cavity.

\section{Acknowledgement}

I wish to thank Mr. John Cook of the Eastern General Hospital, Edinburgh, under whose care the patient was admitted, for permission to report the detail of this case.

Major F. B. MAYES

\section{REFERENCES}

GORDON-TAYLOR (1944) Brit. J. Surg. 32, 247.

Hall, E. R., Howard, J. M., JoRdan, C. L., and Kikesky, W. E. (1956). Arch. Surg. 72, 520.

Pridgen, J. E., Herff, A. F., Watkins, H. O., Halbert, O. S.; D'Avira, R., Crouch, D. M., and Prud'homme, J. L. (1967). Ann. Surg. 165, 901. 